\title{
Determination of the dependence of competitive results on the procedure of sports selection among Greco-Roman wrestling athletes
}

\author{
Nagovitsyn R.S. ${ }^{1 \mathrm{ADE}}$, Osipov A.Yu. ${ }^{2,3,4 \mathrm{ABD}}$, Kapustin A.G. ${ }^{5 \mathrm{BCE}}$, Anfilatova O.V. ${ }^{5 \mathrm{CDE}}$, Senator S.Yu. ${ }^{6 \mathrm{DE}}$ \\ ${ }^{1}$ Glazov State Pedagogical Institute, Russia \\ ${ }^{2}$ Siberian Federal University, Russia \\ ${ }^{3}$ Krasnoyarsk State Medical University named after professor V.F. Voyno-Yasenetsky, Russia \\ ${ }^{4}$ Siberian Law Institute of the Ministry of Internal Affair of Russia, Russia \\ ${ }^{5}$ Vyatka State University, Russia \\ ${ }^{6}$ Moscow Social Pedagogical Institute, Russia
}

Authors' Contribution: A - Study design; B - Data collection; C - Statistical analysis; D - Manuscript Preparation; E - Funds Collection.

\begin{abstract}
Purpose:

the problems of sports selection and selection of prospective children in martial arts schools are quite relevant in the sports practice. It was revealed the use of various selection techniques in the practice of martial arts. There is no unified methodological system for selection in martial arts schools. The purpose of the study: to determine the dependence of the dynamics of sports results of elite athletes on the procedure of sports selection (for example, the Greco-Roman wrestling).

Material: $\quad$ elite athletes $(n=114)$ practicing Greco-Roman wrestling took part in the research. Age of athletes: 25-45 years. Qualification: International masters of sport $(n=8)$, masters of sport $(n=49)$, candidates in masters of sport $(n=57)$. Athletes filled out a diagnostic card with data on the procedure of sports selection. It was indicated the dynamics of competitive results during the sports career. Indicators of performance and stability of athletes were calculated applying the mathematical statistics methods $(\bar{x})$. The reliability of the results was determined by Student's t-test.

Results: $\quad$ Data analysis showed that a significant part of athletes did not pass the selection procedure $(n=23)$. Many athletes passed only a partial selection procedure $(n=39)$. Some athletes did not pass the selection procedure. These athletes are not inferior in terms of stability to athletes who passed the selection at the 1 st and 2 nd levels of competitive results. In subsequent competitions, these athletes demonstrated the reliable $(P<0.05)$ decrease in indicators of stability in comparison with other athletes. It was revealed a significant $(P<0.05)$ advantage in indicators of stability among athletes who passed a partial selection procedure at the 4th level of competitive results.

Conclusions: It was found the dependence of stability indicators at high levels of competitive results on the selection procedure of athletes. The athletes who passed the selection procedure demonstrate higher stability at high levels of competitive results. It was revealed a formal attitude to the selection procedure in some coaches and specialists. The trainers do not pay due attention to the indicators of maintaining body balance and coordination abilities during the selection of candidates. It has been revealed that the motor tests applied in the selection procedure do not allow an objective assessment of the potential of athletes' competitive achievements.

Keywords: martial arts, wrestling, selection, elite athletes, tests, competitive results.
\end{abstract}

\section{Introduction}

The process of many years of training in any sport begins with a procedure of candidates' selection. The selection procedure is aimed at determining the athletic ability and athletic orientation of future athletes. Sports abilities are prerequisites for future sports achievements and the possibility of their progressive development in the sports practice. In increasing the competition in the sport of higher achievements, the demand for identifying talented athletes has increased $[1,2]$. The most important factors in determining athletic abilities are the following: genetic advances [3] and features of the psycho-physiological profile of future athletes $[4,5]$. Factors of biological maturation $[6,7]$, the level of adaptive capacity $[8,9]$ and other characteristics $[10,11]$ are also considered.

The various test batteries are applied in sports for

( ) Nagovitsyn R.S., Osipov A.Yu., Kapustin A.G., Anfilatova O.V.,

Senator S.Yu., 2019

doi:10.15561/18189172.2019.0404 sports selection. The batteries of special tests are applied in the selection for various types of martial arts $[12,13]$. However, it is revealed the lack of specialists' attention to the theoretical foundations and prognostic validity of selection procedures among young athletes [14].

Scientists emphasize the importance of comprehensive testing conducted in identifying the talents of candidates in selecting to the wrestling schools [15]. However, experts point to the lack of valid (reliable and stable) in the selection tests of various types of martial arts [16]. There is no exact methodologically verified system of sports selection in martial arts. Different specialists have different views on the structure and procedure of selection in martial arts. Volodchenko et al., recommends a number of different functional tests for the martial arts selection procedure [12]. However, the authors do not recommend to use these samples to the athletes' functional status monitoring. This decreases their significance level. 
Osipov et al. point to certain criteria for the young athletes' selection practicing judo and sambo (high balance and ability to perform judo techniques) [17]. The authors have revealed the increase in the results of young athletes using certain methods of training sambo and judo. It is recommended to increase the sample and age categories of selecting participants in studies devoted to the determination of the genetic characteristics of martial art athletes. This approach is necessary to increase the reliability of the results [3]. Most of the studies on sports selection in martial arts schools contain significant scientific data. However, there is a lack of data on the methodology, stability and other indicators of the reliability of the presented results. Baker determines some inadequate application of modern statistical approaches to predict future athletic performance in talented children selection [18].

Scientifically-based methods of selecting " talented " young men in martial arts schools become important stages in the system of qualified martial arts athletes training. In the practice of sports selection in schools of martial arts are applied tests to assess the level of physical development and motor abilities of athletes [19]. Experts pay considerable attention to the psychophysiological profile and anthropometric data of athletes [20] during the sports selection. There is data that many martial arts athletes in the selection process don't pass the tests. Also, there is a lack of high-quality motor tests for the selection. The literature presents data that more than half of 425 elite Turkish wrestlers did not pass a qualitative selection procedure [21]. It was found that many coaches do not use objective reliable methods and criteria in the selection process. Experts are guided by their own views on the sport and personal feelings in the selection procedure [22]. The authors determine that coaches do not have a clear understanding of the necessary criteria for highquality sports selection [1].

Modern scientific studies emphasize the need to assess the effectiveness of competitive activities of martial arts athletes [23]. The data of the competitive results of martial arts athletes and the stability of competitive performances of athletes are applied for the evaluation [24]. The level of athletes' competitiveness is an important evaluation criterion [25].

The purpose of the study is to determine the dependence of the sports results dynamics of elite athletes - Greco-Roman style wrestlers on the procedure of sports selection. Also, It was conducted a search for reliable data on the applied methods in sports practice for young athletes selection in Greco-Roman wrestling schools.

\section{Materials and methods}

Participants: men $(\mathrm{n}=114)$ - elite athletes of GrecoRoman wrestling. Age of athletes: 25-45 years. Sports qualifications: elite athletes with sports titles: candidate in masters of sport $(n=57)$, masters of sport $(n=49)$, international masters of sport $(n=8)$. Athletes represented various schools of Greco-Roman wrestling in different regions of the Russian Federation: Tatarstan, Udmurtia,
Perm Territory, Nizhny Novgorod Oblast. The selection criteria of study participants were the following: the prizes at official competitions of a certain level, the sports titles in Greco-Roman wrestling. All participants gave informed consent to participation in the research.

Design of the study: all athletes filled out a diagnostic card in which it was necessary to indicate in detail: A) the procedure and methods of sports selection; B) the level of competition results and results in official competitions for a sports career. It was considered the data of 10 competitive performances of athletes for each level (if there are a sufficient number of performances).

Level of competition results:

№1. Championship of the city, district or youth sports school.

№2. Competition or the championship of the region, republic, All-Russian tournament.

№3. All-Russian official tournament for the award of the title "Master of Sports of Russian Federation".

№4. Competition or championship of the Federal District of Russian Federation.

№5. Competition or championship of Russian Federation, the international official tournament for the title of "International Master of sport".

Athletes had to indicate the highest sports results at each level of competition (not less than 5 and not more than 10 competitive results). Verification of the presented data was carried out using archival materials provided by the Greco-Roman wrestling schools, where athletes were trained.

The analysis of the cards demonstrated that 47 of 114 martial art athletes passed a complete procedure of sports selection. The trainers applied a variety of motor tests during the athletes' selection. The ability of candidates to perform various combat techniques was also tested. These athletes were included in the group № 1. A number of athletes $(n=41)$ indicated the partial selection procedure passing. The motor tests or attempts to perform combat techniques were applied during the selection procedure. These athletes were included in the group №2. The remaining martial arts athletes $(n=26)$ did not indicate in their cards any procedures and methods of sports selection. These athletes were included in the group №3.

Statistical analysis. The mathematical and statistical processing of the results was performed after the obtained data processing. The calculation of the arithmetic mean value $(\bar{x})$ allowed to determine the indicators of performance and stability of each athlete. The first indicator showed the average performance of wrestlers in each level of official competitions. The second indicator determined the stability of athletes at competitions. The ratio of performance indicators and stability allowed to determine the quality of the competitive activity of athletes. The magnitude of the deviation of the numerical value of stability from the value of performance indicates the level of competitive stability of athletes.

Processing of the research results was carried out using the statistical program SPSS20. The significance of differences in the results was determined using Student's 
t-test. Mathematical-statistical processing was carried out between $x$ performance and $x$ stability of elite athletes for each level of competitive activity.

\section{Results}

At the 1st and 2nd stages of competitive activity, there were no significant discrepancies in the results of the athletes. Athletes of all groups showed approximately equal indicators of the ratio of competitive performance and stability. Level 3 revealed significant $(\mathrm{P}<0.05)$ differences between the results of athletes. Less high indicators of the ratio of performance and stability of performances were demonstrated by athletes who did not pass the selection procedure. The ratio of these indicators in athletes of 1 st and 2 nd groups indicates higher stability of competitive performances. It was found a significant $(\mathrm{P}<0.05)$ superiority of athletes from group 2 over the rest of athletes at the 4 th level. At the 5 th (highest) level, athletes of groups 1 and 2 demonstrate a significant $(\mathrm{P}<0.05)$ superiority in performance and stability indicators over athletes of group 3. The data of competitive results of all groups of athletes are presented in table 1.

The level of sports qualification of all groups of athletes is presented in Figure 1

According to the obtained data, 88 athletes passed the sports selection procedure (full or partial). The majority of athletes (91\%) tested for speed-strength abilities. 84\% of athletes were tested for indicators of general endurance development. The level of development of coordination abilities was tested in $52 \%$ of athletes. Response measurements were tested in $36 \%$ of athletes. Ability to perform the wrestling techniques was assessed in $45 \%$ of candidates. The data on certain tests passed by athletes of group № $1(\mathrm{n}=47)$ and group № $2(\mathrm{n}=41)$ are presented in Figure 2.

A - tests for estimation power abilities; B - tests for estimation of speed-power abilities; $\mathrm{C}$ - tests for estimation of the general endurance level; D - tests for estimation of coordination abilities and balance of a body;

Table 1. The ratio of indicators performance and stability of different athletes' groups

\begin{tabular}{llllll}
\hline Athletes & Competition level & & & & \\
$(\mathbf{n = 1 1 4})$ & $\mathbf{1}$ & $\mathbf{2}$ & $\mathbf{3}$ & $\mathbf{4}$ & $\mathbf{5}$ \\
& Result/Stability & Result/Stability & Result/Stability & Result/Stability & Result/Stability \\
\hline Group 1 $(\mathrm{n}=47)$ & $2.13 / 1.89$ & $3.13 / 2.49$ & $3.44 / 2.55$ & $4.17 / 3.65$ & $5.13 / 4.29$ \\
Group 2 $(\mathrm{n}=41)$ & $2.21 / 1.85$ & $3.17 / 2.33$ & $3.65 / 2.93$ & $5.03 / 4.61^{*}$ & $5.24 / 4.67$ \\
Group 3 $(\mathrm{n}=26)$ & $2.14 / 1.67$ & $3.43 / 2.56$ & $4.72 / 3.67^{*}$ & $4.42 / 3.64$ & $4.65 / 3.47^{*}$ \\
\hline
\end{tabular}

Note: * $-\mathrm{P}<0.05$.

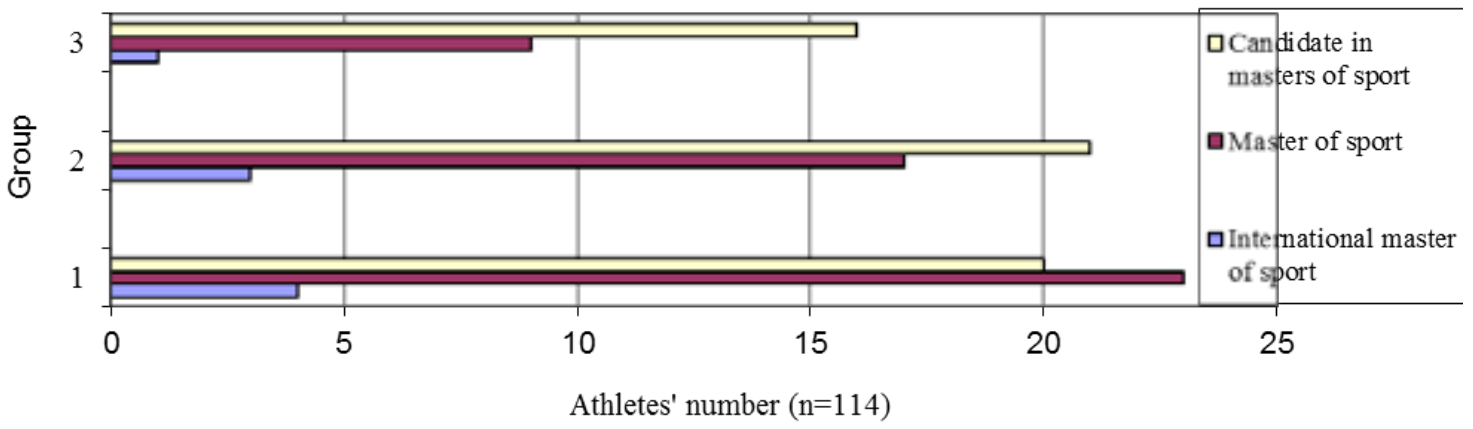

Fig. 1. Data on sports qualifications of athletes in the studied groups.

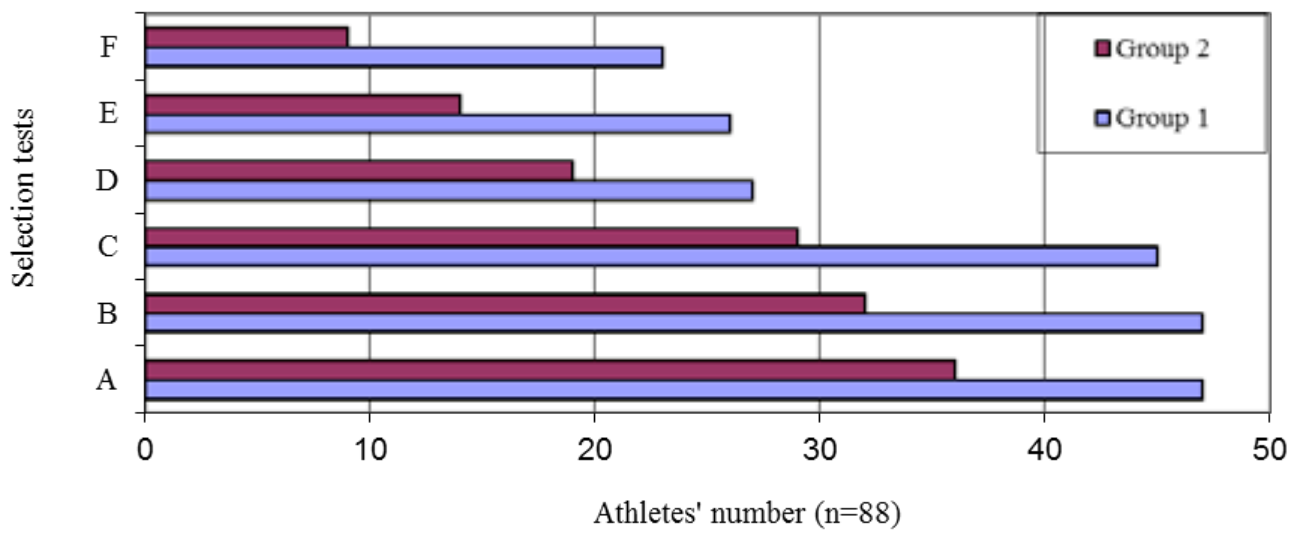

Fig. 2. Data on the number of athletes passed the test. 


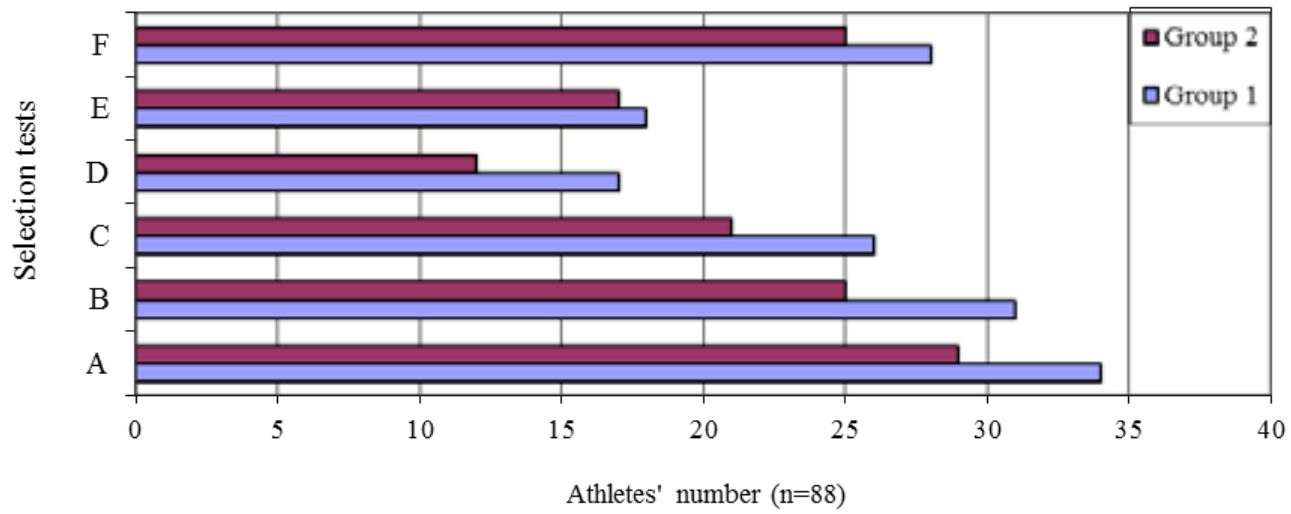

Fig. 3. Data on the number of athletes who have successfully passed the tests.

E - tests for estimation the ability to perform wrestling techniques; F - tests for estimation the reaction speed (simple reaction).

The data on the performance of the sports selection norms by athletes from group №1 and №2 $(\mathrm{n}=88)$ were obtained from the archives of sports schools and data cards. In group $1(\mathrm{n}=47)$, the tests were successfully carried out: power abilities $-72 \%$ of athletes; speedpower abilities $-66 \%$; endurance development $-55 \%$; coordination abilities - 36\%; response measurement $60 \%$; wrestling techniques $-38 \%$ of athletes. In group $2(n=41)$, the tests were successfully completed: power abilities $-71 \%$ of athletes; speed- power abilities $-61 \%$; endurance development - 51\%; coordination abilities $29 \%$; response measurement $-61 \%$; wrestling technique $-41 \%$ of athletes. The group №1 leads according to the total number of athletes who successfully passed the selection procedure. As a percentage, the advantage of athletes of group №2 was revealed in the results of testing the ability to perform wrestling techniques and response measurements. Complete data on the number of athletes who have successfully passed the tests are presented in Figure 3.

\section{Discussion}

Studies confirm the need for high-quality selection among candidates for martial arts schools. Higher rates of competitive stability are demonstrated by athletes who passed various sports selection procedures. However, this advantage is manifested in the competitive practice of high level: in official national championships or international tournaments. In the competitive practice of levels 1 and 2, no significant discrepancies were found between the indicators of competitive performance and stability among athletes of different groups. The absence of significant ratio $\mathrm{s}$ between the selection procedure and the initial competitive results allow the coaches to treat the sports selection procedure quite formally. Experts point to the formal attitude of many coaches to the procedure of sports selection in martial arts [21]. The coaches are not guided by objective criteria in the selection procedure but by their own view of the practice of sports and personal preferences [22]. In our data, the selection procedure in various tests successfully passed from 30 to $70 \%$ of athletes. The rest of the athletes were enrolled in GrecoRoman wrestling schools on the subjective decision of the coach. It can be recognized that many sports specialists and coaches do not consider the procedure of sports selection as an objective and mandatory one. Experts determine the significant differences in the coaches' views on the methodological criteria for the practice of wrestling [26]. Many coaches subjectively determine the criteria for assessing the abilities of young combat athletes. Scientifically based methods are not considered. For example, the selection does not consider the ability of young athletes to ambidexterity (performance of wrestling techniques in the right and left sides). It is accepted that this feature will not affect sports performance at the beginning of competitive activities [27].

It should also discuss the tests applied in the selection process for martial arts schools. Most of the tests allow the evaluation of physical [19], technical [15], physiological [12] and psychological skills of candidates in controlled conditions [14]. In Russian wrestling schools, the testing procedure is the performance of certain standards for the physical and functional fitness of candidates. In the practice of wrestling, special indices are applied to assess the level of motor abilities of athletes. Indices are numerical (ball) values of the results of performing special motor tests that characterize the state of combat athletes [28]. Scientists define this assessment system allows to assess objectively the motor potential and future sports achievements of athletes [15]. The literature presents data on the incompatibility of a number of indicators of elite combat athletes with certain index values. The indicators of the power and flexibility development did not meet the standards of the national team in the multiple world champion in Greco-Roman wrestling [29]. Consequently, the numerical indices of motor abilities do not allow experts to reliably determine the final potential of athletes' competitive achievements. Qualitative analysis of tests is possible only with the long-term monitoring of sufficient samples of athletes. Most studies consider a small in number (from several tens to several hundred) samples of athletes [30]. To increase the reliability of data, it is necessary to increase the number and age groups of candidates in selecting procedure to the martial arts schools [3]. 
There are recommendations that suggest considering the level of athletes' coordination abilities development in the selection procedure to the schools of Greco-Roman wrestling [16]. In our data, high levels of coordination abilities were found on average in $32 \%$ of the athletes who passed the selection procedure. The data reflects the position of the majority of Russian coaches to the criteria for the effectiveness of sports selection in martial arts - high rates of power and speed- power abilities. Our data show high rates of development of speed- power and power abilities in $65 \%$ of athletes. Researchers point out that power indicators cannot be considered as a completely objective criterion for effective selection in martial arts. The coordination potential of athletes is an important criterion for success in the martial arts [31]. It was revealed that high levels of coordination and body balance have a positive effect on athletes' competitive results [32]. Specialists in the field of sports selection should pay attention to the indicators of coordination and balance of the body, during the selection to the martial arts schools.

Researchers emphasize the high ratio between the indices of the motor reaction of athletes and the result of competitive matches in Greco-Roman wrestling [23]. Finalists and winners of elite competitions (as a rule) have a higher response time rate than wrestling athletes who lost the tournament [33]. Our data show the presence of high rates of response rate in the selection of an average of $60 \%$ of athletes. This criterion is informative for determining the success of competitive activities. At the same time, response rates are not a determining factor for coaches when enrolling candidates in wrestling schools.

\section{Conclusions}

1. It was revealed a significant dependence of the ratio of competitive performance indicators and the athletes' stability of the procedure of sports selection. Higher rates of competitive stability in high-level competitions are shown by athletes who passed the selection procedures.

2. It was found out the discrepancy to certain test criteria in selecting procedure in a significant number of athletes. It was determined the compliance with the selection criteria in motor tests in $30-70 \%$ of combat athletes. Significant competitive results were found in athletes who showed different test results. Some criteria and tests do not allow to evaluate completely the competitive potential of athletes during the sports selection.

3. It was revealed that many coaches in the selection procedure did not pay enough attention to the indicators of the body balance and coordination abilities development of candidates. According to experts, a high level of coordination and body balance development contributes to the growth of competitive results.

\section{Restrictions}

The results of the study have some restrictions. The analysis of the presented data was made considering the athletes' subjective data to the procedure and methods of sports selection. We tried to confirm the data of athletes with archival materials from the Greco-Roman wrestling schools, but this was not possible in all cases.

\section{Conflict of interest}

The authors declare that there is no conflict of interest.

\section{References}

1. Rees T, Hardy L, Güllich A, Abernethy B, Côté J., Woodman $\mathrm{T}$, et al. The great British medalists project: A review of current knowledge on the development of the World's best sporting talent. Sports Medicine. 2016;46:1041-1058. https://doi.org/10.1007/s40279-016-0476-2

2. Oleksy M, Kalina RM, Mosler D, Jagiello W. Quasiapparatus shime waza test (QASWT) - validation procedure. Archives of Budo. 2018;14:133-147.

3. Bondareva E, Godina E, Lkhagvasuren G, Bleer A. Sports qualification in different kinds of martial arts (case stady of polymorphic systems of ACE and ACTN3 genes). Teoriya $i$ Praktika Fizicheskoy Kultury. 2015;8:94-97.

4. Isaev A, Korshunov A, Leonov S, Sanoyan T, Veraksa A. Quantitative and qualitative indicators of developing anticipation skills in junior wrestlers athletes. Procedia - Social and Behavioral Sciences. 2016;233:186-191. https://doi.org/10.1016/j.sbspro.2016.10.191

5. Podrigalo L, Iermakov $\mathrm{S}$, Romanenko $\mathrm{V}$, Rovnaya O, Tropin Y, Goloha V, et al. Psychophysiological features of athletes practicing different styles of martial arts - the comparative analysis. International Journal of Applied Exercise Physiology. 2019;8(1):84-91. https://doi.org/10.30472/ijaep.v8i1.299

6. Müller L, Müller E, Hildebrandt C, Kapelari K, Raschner C. The assessment of biological maturation for talent selection - which method can be used? Sportverletz Sportschaden. 2015;29(1):56-63. https://doi.org/10.1055/s-0034-1399043

7. Jagiello W, Jagiello M, Kalina RM, Barczynski BJ, Litwiniuk A, Klimczak J. Properties of body composition of female representatives of the Polish national fencing team - the sabre event. Biology of Sport. 2017;34(4):401-6. https://doi.org/10.5114/biolsport.2017.70526

8. Tayebi S, Mahdian H, Mahmoudi S. Short-term adaptation of some iron indices of young elite wrestlers to three types of aerobic, anaerobic, and wrestling training. International Journal of Applied Exercise Physiology. 2016;5(1):11-16.

9. Jagiello M, Iermakov SS, Nowinski M. Differentiation of the somatic composition of students physical education specialising in various sports. Archives of Budo Science of Martial Arts and Extreme Sports. 2017;13:63-70.

10.Surina-Marysheva E, Erlikh V, Medvedeva I, Korableva Yu, Kantyukov S. Heart rate variability features in elite hockey players aged 15-16 and sports selection efficiency in youth ice hockey. Human. Sport. Medicine. 2018;18(4):47-51.

11.Kriventsova I, Iermakov S, Bartik P, Nosko M, Cynarski WJ. Optimization of student-fencers' tactical training. Ido Movement for Culture-Journal of Martial Arts Anthropology, 2017;17(3):21-30. https://doi.org/10.14589/ido.17.3.3

12. Volodchenko O, Podrigalo L, Aghyppo O, Romanenko $\mathrm{V}$, Rovnaya O. Comparative analysis of a functional state of martial arts athletes. Journal of Physical Education and Sport. 2017;17(Suppl. Issue 4):2142-2147. https://doi.org/10.7752/jpes.2017.s4220 
13. Volodchenko OA, Podrigalo LV, Iermakov SS, Zychowska MT, Jagiello W. The Usefulness of Performing Biochemical Tests in the Saliva of Kickboxing Athletes in the Dynamic of Training. Biomed Research International. 2019. https://doi.org/10.1155/2019/2014347

14.Den Hartigh R, Niessen A, Frencken W, Meijer R. Selection procedures in sports: Improving predictions of athletes' future performance. European Journal of Sport Science. 2018;18(9):1191-1198. https://doi.org/10.1080/17461391.2018.1480662

15.García-Pallarés J, López-Gullón J, Muriel X, Díaz A, Izquierdo M. Physical fitness factors to predict male Olympic wrestling performance. European Journal of Applied Physiology. 2011;111(8):1747-1758. https://doi.org/10.1007/s00421-010-1809-8

16.Chaabene H, Negra Y, Bouguezzi R, Capranica L, Franchini $\mathrm{E}$, et al. Tests for the assessment of sport-specific performance in Olympic combat sports: A systematic review with practical recommendations. Frontiers in Physiology. 2018. https://doi.org/10.3389/fphys.2018.00386

17.Osipov A, Guralev V, Kudryavtsev M, Kamoza T, Kuzmin $\mathrm{V}$. Development of the ability to maintain body balance in dynamic conditions in beginning sambo wrestlers aged 1112. Human. Sport. Medicine. 2018;18(4):88-94.

18.Baker J, Schorer J, Wattie N. Compromising talent: Issues in identifying and selecting talent in sport. Quest. 2018;70(1):48-63. https://doi.org/10.1080/00336297.2017.1333438

19.Bulğay C, Çetin E. Examination of physical, motor and physiological features of athletes and wrestlers in the age group of 12-14 years old in terms of branching. International Journal of Applied Exercise Physiology. 2017;7(1):1-10. https://doi.org/10.22631/ijaep.v7i1.152

20.Marques V, Coswig W, Viana R, Leal A, Alves F, et al. Physical fitness and anthropometric measures of young Brazilian judo and wrestling athletes and Its relations to cardiorespiratory fitness. Sports. 2019;7(2):38. https://doi.org/10.3390/sports7020038

21.Kaynar Ö, Bilici F. Analysis of the talent selection in Turkish wrestling. International Journal of Science Culture and Sport. 2017;5(4):347-355. https://doi.org/10.14486/IntJSCS698

22.Johansson A, Fahlén J. Simply the best, better than all the rest? Validity issues in selections in elite sport. International Journal of Sports Science \& Coaching. 2017;12(4):470-480. https://doi.org/10.1177/1747954117718020

23.Gierczuk D, Lyakh V, Sadowski J, Bujak Z. Speed of reaction and fighting effectiveness in elite Greco-Roman wrestlers. Perceptual and Motor Skills. 2017;124(1):200-213. https://doi.org/10.1177/0031512516672126
24.Koptev O, Osipov A, Kudryavtsev M, Zhavner T, Vonog V, Fedorova $\mathrm{P}$, et al. Estimation degree of changes influence in competition rules on the contests ratios of judo wrestlers of lightweight categories in Russia and Kyrgyzstan. Journal of Physical Education and Sport, 2017; 17(Suppl. Issue 4):2067-2072. https://doi.org/10.7752/jpes.2017.s4209

25.Barkov A. Securing university wrestlers' technical and tactical progress based on competitive performance quality profiling data. Teoriya $i$ Praktika Fizicheskoy Kultury. 2017;1:53-55.

26.Campos LJ, Godoy PE, Agostini PB, Marques AA, Pereira SF. Pedagogical knowledge of teaching fights by trainers in an informal environment. Human Movement. 2018;19(4):11-19. https://doi.org/10.5114/hm.2018.77319

27.Nagovitsyn R, Zhuikova S, Kondratiev N, Osipov A, Zhavner T, Vapaeva A. Influence of sports asymmetry and ambidexterity of ground wrestling on the level of competitive performance of Greco-Roman style wrestlers. Journal of Physical Education and Sport. 2018;18(4):2472-2477. https://doi.org/10.7752/jpes.2018.04370

28.Starosta W., Rynkiewicz T. Test battery for the evaluation and assessment of movement abilities in elite Polish wrestlers. International Journal of Wrestling Science. 2014;4(1):49-55. https://doi.org/10.1080/21615667.2014.10879000

29.Mirzaei B, Curby D, Barbas I, Lotfi N. Anthropometric and physical fitness traits of four-time World Greco-Roman wrestling champion in relation to national norms: A case study. Journal of Human Sport and Exercise. 2011;6(2):406-413. https://doi.org/10.4100/jhse.2011.62.21

30.Demirkan E, Kutlu M, Koz M, Ozal M, Favre M. Physical fitness differences between freestyle and Greco-Roman junior wrestlers. Journal of Human Kinetics. 2014;41:245-251. https://doi.org/10.2478/hukin-2014-0052

31.Bolotin A, Bakayev V. Pedagogical practice for development of coordination potential of MMA fighters and estimation of its efficiency. Journal of Human Sport and Exercise. 2018;13(1):72-88. https://doi.org/10.14198/jhse.2018.131.08

32.Morán-Navarro R, Valverde-Conesa A, López-Gullón J, De la Cruz-Sánchez E, Pallarés J. Can balance skills predict Olympic wrestling performance? Journal of Sport and Health Research. 2015;7(1):19-30.

33.Gierczuk D, Bujak Z, Cieslinski I, Lyakh V, Sadowski J. Response time and effectiveness in elite Greco-Roman wrestlers under simulated fight conditions. Journal of Strength and Conditioning Research. 2018;32(12):3433-3440. https://doi.org/10.1519/JSC.0000000000002868 


\section{Information about the authors:}

Nagovitsyn R.S.; (Corresponding author); doctor of pedagogical sciences, associate professor; http://orcid.org/0000-00034471-0875; gto18@mail.ru; Glazov State Pedagogical Institute; Pervomaiskaya Street, 25, Glazov, 427620, Russia.

Osipov A.Yu.; candidate of pedagogical sciences, associate professor; http://orcid.org/0000-0002-2277-4467; ale44132272@ yandex.ru; Siberian Federal University; 79 Svobodny pr., Krasnoyarsk, 660041, Russia; Krasnoyarsk State Medical University named after professor V.F. Voyno-Yasenetsky; P. Zeleznyak, 1, Krasnoyarsk, 660022, Russia; Siberian Law Institute of the Ministry of Internal Affair of Russia; Rokossovskia Street, 20, Krasnoyarsk, 660131, Russia.

Kapustin A.G.; candidate of pedagogical sciences, associate professor; https://orcid.org/0000-0001-8655-4060; usr11637@ vyatsu.ru; Vyatka State University; Orlovskaya Street, 12, Kirov, 610007, Russia.

Anfilatova 0.V.; candidate of pedagogical sciences, associate professor; https://orcid.org/0000-0002-0412-2553; usr11509@ vyatsu.ru; Vyatka State University; Orlovskaya Street, 12, Kirov, 610007, Russia.

Senator S.Yu.; doctor of pedagogical sciences, professor; http://orcid.org/0000-0002-0779-9199; s-senator@yandex.ru; Moscow Social Pedagogical Institute; Friedrich Engels Street, 75, Moscow, 105082, Russia.

Cite this article as:

Nagovitsyn RS, Osipov AYu, Kapustin AG, Anfilatova OV, Senator SYu. Determination of the dependence of competitive results on the procedure of sports selection among Greco-Roman wrestling athletes. Pedagogics, psychology, medicalbiological problems of physical training and sports, 2019;23(4):182-188.

https://doi.org/10.15561/18189172.2019.0404

This is an Open Access article distributed under the terms of the Creative Commons Attribution License, which permits unrestricted use, distribution, and reproduction in any medium, provided the original work is properly cited (http://creativecommons.org/licenses/by/4.0/deed.en).

Received: 08.05.2019

Accepted: 12.06.2019; Published: 29.08.2019 